\title{
ENTRE O HISTÓRICO E O FICCIONAL: A SOMBRA DOS DOCUMENTOS EM FE EN DISFRAZ, DE MAYRA SANTOS-FEBRES
}

BETWEEN THE HISTORICAL AND THE FICTIONAL: THE SHADOW OF THE DOCUMENTS IN FE EN DISFRAZ, BY MAYRA SANTOS-FEBRES

Júlia Morena Costa* Eliene Santana dos Santos**

RESUMO: Este ensaio se dedica a discutir a relação entre o real e o ficcional nos documentos constantes no romance $F e$ en disfraz (2009), de Mayra Santos-Febres (1963, Porto Rico), como forma de criação de zonas de afetaçáa dos leitores e de revisáo de um passado histórico violento. A partir da análise do romance, que intercala o presente dos protagonistas com documentos do passado escravocrata latino-americano, com especial atenção à violencia que recai sobre o corpo de mulheres negras, propoe-se uma reflexăo sobre as potencialidades do real no espaço narrativo. No embaralhamento dos registros históricos e ficcionais, com informaçoes confirmáveis e de reconhecido registro documenta no romance, propoe-se discutir as potencialidades da ficção que toma suposta legitimidade do real como estrategia que possa visibilizar e fortalecer narrativas outras que reinserem os corpos de mulheres negras na história oficial e literária a partir da chave da dignidade.
PALAVRAS-CHAVE:
Real; Representação;
Violência;
Mayra

* juliamorenacosta@gmail.com

Doutora em Literatura e Cultura pela Universidade Federal da Bahia, mestre em Teoria da Literatura pela Universidade Federal de Minas Gerais e graduada en Letras também pela UFMG. Atualmente e professora Adjunto do Instituto de Letras da Universidade Federal da Bahia, atuando na graduação e no programa de pós graduaçăo em Literatura e Culfira

Mestranda em Literatura e Cultura (UFBA/2018). Graduada em Letras Vernáculas - Porcus atividades educacionais no Projeto Social Instituto Quilombo llha na cidade de Vera Cruz -BA (2012). Bolsista do Programa Milton Santos.

ABSTRACT: This essay is dedicated to debate the relationship between the real and the fictional in the documents contained in Mayra SantosFebres' (1963, Puerto Rico) novel Fe en disfraz (2009), as a way of creating readership zones and revision of a violent historical past. From the analysis of the novel, which interleaves the present of the protagonists with documents of he Latin American Enslavement past, with special attention to the violence that falls on the body of Black women, it is proposed a reflection on the potentialites of the real in the narrative space. In the shuffling of historical and fictional records, with confirmatory information and recognized documentary record in a novel, it is proposed to discuss the potential of fiction that takes the supposed legitimacy of the real as a narrative strategy that can make visible and strengthen other narratives that reinsert the bodies of black women in official and literary history from the key of dignity.

KEYWORDS: Real; Representation; Violence; Mayra Santos-Febres1. 
A primera vista todo parece distinto. La edad de Piedra, la Revolución industrial, la Guerra Fría. Es debajo, muy por debajo de los siglos y de las eras que se comienza a avistar la imperturbable eterni-

dad de lo real

(Mayra Santos Febres)

A noite não adormece nos olhos das mulheres há mais olhos que sono onde lágrimas suspensas

virgulam o lapso de nossas molhadas lembranças

(Conceição Evaristo)

Sabemos que toda história, por mais conhecida que seja, não está ainda, e talvez nunca, totalmente contada. Diante do intenso questiona mento quanto às vozes hegemônicas que, por tanto tempo, dominara $\mathrm{m}$ os discursos historiográficos, o resgate da memória de "desconhecidos" pode trazer novos lados para o significado histórico de contextos que já se pensava m bem conhecidos. Por isso, é sempre um exercício democrático se propor a revisar e remontar a história a partir das vozes que não a contaram. Ainda que esses relatos surjam justamente a partir de sua ausência, como é o caso das narrativas de escravizados, e ainda menos presentes, de mulheres escravizadas na América Latina. Este ensaio se propõe a abordar, pela via do discurso literário, as revisitações ficcionais e documentais do período escravagista latino-americano na novela porto-riquenha $\mathrm{Fe}$ en disfraz. Mayra Santos-Febres a firma na nota da autora que Fe en Disfraz é muitas coisas, mas, ta mbém, é um romance sobre a memória e a ferida que é recordar. (FEBRES 2009, p.109). Nesse sentido, a leitura dessa obra propõe o mergulho em um passado que envergonha a história da humanidade, uma vez que aborda as violências sofridas pelas mulheres negras no período da escravização em vários países da América Latina e evidencia que, até hoje, "existe um olhar colonizador sobre nossos corpos, saberes, produções e, para além de refutar esse olhar, é preciso que partamos de outros pontos." (RIBEIRO, 2017, p.35).

De acordo com Giovana Xavier (2012, p.67), "alvo de diferentes projetos de intervenção durante a escravidão ${ }^{1}$ africana nas Américas, o corpo da mulher negra foi visto como um misterioso pedaço de carne a ser dissecado". Ela segue afirmando que isso era reproduzido não apenas nas falas dos senhores ou viajantes europeus, mas igualmente "em ricas e detalhadas narrativas de médicos, juristas, policiais, figurando ta mbém nos anúncios de compra, venda e fuga de escravas [...]”. (p.67). Dessa maneira, as imagens
1. Sinalizamos que, embora
optemos pelo uso de termos como escravização e escravizados/ escravizadas, mantivemos a grafia original das citações em respeito aos autores/as 
produzidas nessa época constroem um intricado tecido narrativo científico, documental e ficcional que desmerece as subjetividades negras e se refletem até hoje na vida desses seres humanos que sofrem com o racismo estrutural e estruturante.

Nesse cenário, a literatura teve um papel importante, pois atuou como reprodutora de discursos preconceituosos, forjando representações negativas e estereotipadas sobre os afrodescendentes e que ao longo do século XVIII "suas imagens foram utilizadas por diferentes escritores como metáfora da patologia, da corrupção e do primitivismo, configurando o corpo feminino negro como doente e, portanto, nocivo a saúde de uma nação em construção." (XAVIER, 2017, p. 67). Comumente associadas a um corpo 'não domesticado' ou a uma sexualidade exacerbada, tendo sua representação de forma, geralmente, animalizada ou objetificada. A partir desse projeto literário que se esforçou em divulgar representações preconceituosas e deturpadas surgiram obras que revela $\mathrm{m}$ traços violentos da sociedade da época ao desenhar as "tipologias literárias como as da bela mulata, da crioula feia, da escrava fiel, da preta resignada, da mucama sapeca ou ainda da mestiça virtuosa". (XAVIER, 2017, p. 67, grifos do autor)

Diante disso, na contemporaneidade, a literatura tem sido um ambiente reivindicado pelas escritoras negras que buscam esse "espaço privilegiado de produção e reprodução simbólica de sentidos” (EVARISTO, 2005, p.52), a fim de construir novas representações e novas epistemes. Nesse cená rio literário, Mayra Santos-Febres, em Fe en disfraz, surge como uma escritora que confere espaço e voz a personagens escravizadas, sob uma perspectiva feminina negra, oportunizando seus direitos de fala, expondo as diversas modalidades de violências sexua is sofridas por estas mulheres. E em concordância com o que a firma Conceição Evaristo $(2005$, p. 54) quando diz que "se há uma literatura que nos invisibiliza ou nos ficcionaliza a partir de estereótipos vários, há um outro discurso literário que pretende rasurar modos consagrados de representação da mulher negra na literatura".

Assim, o mesmo campo literário que foi palco para difusão de discursos negativos sobre a sexualidade e o corpo da mulher negra, hoje, se vê sendo ta mbém espaço de novos discursos que caminham na direção de contribuir com novos sentidos que possam dar fim a essas violências. $\mathrm{O}$ que proporciona visibilidade a esses corpos e suas, devolvendo-lhes sua dignidade que é de direito. Pois, "a literatura é poder, poder de convencimento, de alimentar o imaginário, fonte inspiradora do pensamento e da ação". (CUTI, 2010, p. 12). 
A novela Fe en disfraz (2009), de autoria de Mayra SantosFebres (Porto Rico, 1966), porto-riquenha negra e acadêmica, é uma empreitada transnacional pelo atlântico negro que liga o passado e o presente, apresentando diversas histórias de mulheres escravizadas, no Brasil, Costa Rica, Porto Rico, Venezuela dentre outros países que fizeram parte do processo diaspórico, durante a colonização portuguesa e espanhola. São narrativas vivenciadas pela personagem $\mathrm{Fe}$ Verdejo, uma mulher negra, venezuelana e museógrafa. E narradas por seu auxiliar e a mante Martín Tirado, homem branco (e reprodutor de sexismos e racismos velados), conhecedor do mundo digital, subordinado de Fe nas suas pesquisas e nas suas aventuras sexuais.

O romance se desenlaça a partir do achado de uma coleção com documentos sobre mulheres escravizadas alforriadas de diversas regiões dos impérios português e espanho e nos quais se registrava como conseguiram se liberar do jugo da escravização. Narra-se, desses documentos, que algumas tornaram-se, ainda, fazendeiras ou donas de outros bens que lhes garantisse autonomia financeira. Outros documentos relatava $m$ abusos que levaram as escravizadas a pedir ajuda ao Santo Oficio e, além disso, declarações de atormentações e castigos, relatos minuciosos de estupros com conteúdo bastante violento. São documentos de diferentes momentos e de diferentes geografias (1785-Tejuco,
Brasil; 1719, Costa Rica; 1743, Cartagena de Índias; 1645 , Venezuela; 1985, Maracaibo, Fe Verdejo), salpicando toda a América Latina e traçando proximidades históricas entre os diversos e múltiplos territórios do continente, unidos por um passado violento.

Com a função expressa dos personagens Martín e Fe de recompor o passado, Fe en disfraz intercala com os efeitos do presente a reunião de uma série de documentos de mulheres alforriadas vítimas de violência sexual que conseguiram por vias judiciais e acordos, algum tipo de reparação material. O romance, então, monta em paralelo o compilado documental e sua narrativa do presente - relatando os processos da pesquisa e as tentativas de Martín de se relacionar ao mesmo tempo com Fe Verdejo e com sua noiva, branca como ele. Há, nessa ação de Martin, uma explícita analogia com os homens do passado que usavam de sua posição masculina para as 'conquistas' sexuais. Intercalando essa narrativa, se encontram os de relatos oficiais, com histórias de processos de petições, violências sexuais e morais de mulheres que, por maus tratos, violações, favores sexuais ou paga mento, conseguiram sair da condição de escravizadas, subvertendo o sistema escravocrata e garantindo condições materiais de sobrevivência. Dentre esses documentos, alguns se referem a personagens históricos já conhecidos e documentados no mundo extra-ficcional, como o brasileiro 
2. “La historia está llena de mujeres anonimas que lograron sobrevivir a deseo del amo desplegándose ante su mirada. Pero nunca se abrieron completas. De alguna forma, con lo oculto ¿Cómo hicieron que la piel se ofrecerá sin traicionar lo que tenía que permanecer escondido? ¿Cómo hacer ahora para que es piel cuente la verdadera historia de estos seres que accedieron a la esfera limitadisima de su libertad, a cambio de un asco disfrazado devoración sagrada?" de Chica da Silva, que estabelece uma relação com um homem branco que lhe garantirá uma vida de luxos materiais ainda que sem as garantias do reconhecimento social, exclusivo às mulheres brancas. Diante desses relatos, Martín se pergunta:

A história está cheia de mulheres anônimas que conseguiram sobreviver ao desejo do amo desdobrando-se frente ao seu olhar. Mas nunca se abriram completamente. De alguma forma, conseguiram sustentar um jogo doloroso com o oculto Como fizeram para que a pele se oferecera sem trair o que tinha que permanecer escondido? Como fazer agora para que essa pele conte a verdadeira história destes seres que acederam à esfera limitadíssima da sua liberdade, em troca de um asco disfarçado de ardor, de uma violência feita como devoração sagrada? (SANTOS-FEBRES, 2012, p. 46). ${ }^{2}$

Fe Verdejo, acadêmica, pesquisadora negra, por sua vez se interessa pelo passado de mulheres que, como ela, carregam no corpo e na tez negra um passado com severos ecos no presente. Ainda que sua condição de acadêmica mundialmente respeitada por vezes pareça apagar esse lastro do passado, Fe não o esquece. Citamos:

Com quem essas mulheres se parecem?

Não é óbvio, Martín?
Elas se parecem comigo.

Eu continuei olhando $\mathrm{Fe}$, em silêncio. Curiosamente, nunca antes tinha parado para pensar que suas escravas se pareciam com ela. Que ela, presente e ante a mim, tivesse a mesma cor, o mesmo corpo que uma escrava agredida há mais de duzentos a nos. Que o objeto de seu estudo estivesse tão perto de sua pele (SANTOS-FEBRES, 2009, p.53). ${ }^{3}$

$\mathrm{Fe}$, ao contrário de Martín, faz um esforço por encontrar laços que a atem a esse passado que conforma socialmente o corpo da mulher negra. Em uma atração que, por vezes, se faz inclusive erótica, $\mathrm{Fe}$ (re)vive esse corpo, impingindo rasgos físicos, lacerações e vestindo as indumentárias de Chica da Silva, refazendo uso dos tecidos do vestido e da história para viver o seu presente na relação com o corpo do homem branco, porém, dessa vez, em condição de dominante e dominado invertidos. Fe, ao se frustrar com os processos de branqueamento na sua juventude, reflete:

Eu queria ser como aquelas freiras, brancas, puras, como aquelas princesas; vestir trajes até o chão, feitos de veludo bordado com fios de ouro e jóias. Mas, no meu coração, eu sabia que aquilo não era para mim. As alunas do colégio era quem me lembravam disso e a cor da minha pele. Minha pele era o mapa dos meus antepassados. Todos nus, sem brasões ou bandeiras para identificá-los; marcada pelo esquecimento ou,
3. "-A quiénes se habrán parecido esas mujeres?-iNo es obvio Martín? Se parecían a mí.Me quedé mirando a $\mathrm{Fe}$, en silencio. Curiosamente, nunca antes me había detenido a pensar que sus esclavas parecieran. Que ella, presente y ante mí, tuviera la misma tez, el mismo cuerpo que una esclava agredida elobjo de su estudio estuviera tan cerca de su piel" (SANTOS-FEBRES, 2009, p.53).
EM TESE
BELO HORIZONTE
v. 26
N. 1
JAN-ABR. 2020
MARINGOLO; MARRA. Literatura Afro-brasileira: textualidade e corporeidade. P. 32-41 
4. "Yo quería ser como aquellas monjas, blancas, puras, como aquellas princesas; vestir trajes hasta el suelo, hechos de terciopelo bordado con hilos de oro y pedrerías. Pero, en mi fuero interno, Me lo recordan colegio y el color de mi piel. $\mathrm{Mi}$ piel era el mapa de mis ancestros. Todos desnudos, sin blasones $n$ banderas que los identificaran marcados por el olvido o, apenas, por cicatrices tribales, cadenas por las huellas del carimbo sobre lomo. Ninguna tela que me cubriera ni sacra ni profana, podría oculta

FEBRES, 2009, p. 89). ainda, pelas cicatrizes tribais, correntes e pelos trilhos do carimbo nas costas. Nenhum pano que me cobrisse, nem sagrado nem profano, poderia esconder minha verdadeira natureza (SANTOS-FEBRES, 2009, p.89). ${ }^{4}$

Como a firmado a nteriormente, o mote do romance, que trará a pesquisa de $\mathrm{Fe}$ e seu reconhecimento subjetivo no relatado, são os registros oficias referentes a mulheres manumissas. Essas cédulas, que se apresentam interpoladas à narrativa do presente de $\mathrm{Fe}$, se configuram como os documentos recompilados pela historiadora em suas pesquisas e movem uma estética de grande parecença com documentos reais. Há, ainda, uma decodificação de vocabulá rio, forma e conteúdo de documentos similares que provoca, no leitor, um registro de realidade que rompe a barreira distanciadora da ficção e reestabelece a proximidade do jogo com o real. Ressalta mos ainda o uso de personagens históricos extra-ficcionais inseridos entre os relatos extrapolando o âmbito ficcional, como o da já mencionada Chica da Silva. Essa conformação gera um embaralhamento entre os campos do real e do ficcional e o "isso foi" se sobrepõe a uma possível indiferença ou distanciamento com a obra ficcional pertencente ao registro literário. Assim, a legitimidade do real se impõe sobre a já decodificada a mbiência da ficção. Esse jogo de inserção de um suposto real na narrativa ficcional emaranha os registros de uma novela que faz grande uso de contextos históricos ta mbém verificáveis, causando a suspensão do entendimento de que seria possível supor uma fronteira clara e definida entre história e ficcionalidade.

No entanto, embora assuma uma estética com a função expressa de documentos 'reais' dos séculos passados, com datas, termos jurídicos e aparentemente apenas descritivo, os relatos contradizem sutilmente uma possibilidade de registro dessa época da justiça, que era abertamente brancocentrada e masculina, e faz ênfase nas dores das mulheres negras e não nas perdas materiais das famílias e dos homens brancos. Esses documentos, assinados e escritos por homens brancos em posição de poder político ou jurídico dos séculos passados, informam, inclusive, o que a justiça não poderia informar, como os sentimentos pessoais dessas mulheres, a vergonha e a humilhação sofrida por elas. Ou seja, apesar da assinatura masculina e jurídica, a perspectiva, as dores e a sensibilidade criada, por fim, são sobre as mulheres negras e violentadas. Há aqui, portanto, um duplo jogo entre o real e o ficcional. Se, em um primeiro momento há a similaridade com o registro documental em forma, provocando a 'legitimidade' e autenticidade de laudas dos séculos XVIII e XIX em uma leitura mais atenta, esse jogo se desfa $z$ ao inserir na arena das fronteiras, de forma perspicaz, um discurso

EM TESE

BELO HORIZONTE

v. 26

N. 1

JAN.-ABR. 2020

MARINGOLO; MARRA. Literatura Afro-brasileira: textualidade e corporeidade. P. 32-41 
que não poderia estar ali. Usa-se do efeito do documental para provocar uma rasura na arena da normalização da exploração do corpo dessas mulheres, em uma perspectiva feminista e afrocentrada.

Esse jogo, portanto, provoca um duplo movimento, de entrar e sair do registro de suposto real no romance, embaralhando as fronteiras e usando de um efeito potente de legitimidade e aproximação para inserir outra perspectiva. Ao utilizar à decodificação dos documentos reais, com sua potência de registro de uma realidade, a a utora provoca uma ruptura no discurso hegemônico branco e masculino e lança mão de relatos que, travestidos do discurso de poder, instauram um novo espaço de compartilhamento de um sensível ignorado pela história: as dores e vivências dessas mulheres invisibilizadas pelo discurso histórico oficial. (RANCIÈRE, 2005). O romance (re)cria o espaço do real, para inserir o discurso que nunca pôde estar nos espaços legitimados, sensibilizando o leitor para uma possível reconstrução histórica, agora com uma outra ótica. Esse jogo de inversão de discursos é sutil e, por isso mesmo, consegue manter sua potência de instaurar esse outro espaço de criação de afetos sociais, como definiria Safatle (2016).

Parece-nos importante ainda, atentar para um suposto detalhe: há, em cada relato, uma informação aparentemente gratuita que é a origem étnica dessas mulheres. Essa informação sutil apresenta uma carga de relinhagem para os povos que na diáspora forçada se viram violentados ta mbém no reconhecimento e manutenção dos laços com suas origens. Esse 'detalhe' provoca um mapea mento étnico e recompõe uma identidade negada e invisibilizada dessa população que teve que lidar com as mais diversas formas de violência, entre elas, a negação de um pertencimento e reconhecimento histórico e étnico válidos. Essa informação soma-se com a perspectiva sensível ao sofrimento das mulheres abordadas e funda espaços de resistência dentro do discurso oficial de opressão.

Esse jogo entre o real e o ficcional estabelecido nos relatos que aludem a mulheres com referências verificáveis em documentos históricos extra-literários se estabelece sem interrupções, até que uma das cédulas apresentadas, a última, é da própria Fe Verdejo, personagem ficcional do romance. O relato, já no século XX (1985), contado em primeira pessoa pela personagem, descreve sua infância no monastério e o caso de estupro perpetrado por um homem branco contra a própria pesquisadora quando tinha quinze a nos de idade. O relato, assim como os demais, se faz a partir da decodificação estética de um documento oficial, usando as mesmas indicações de formato que os demais papeis históricos apresentados anteriormente. 
5. "Abuela Raquel había dispuesto de todo, hasta del parejo que me acompañaría a mi baile de escogió a Aníbal Andrés, ahijado de una sobrina. El muchacho er blanco como la nieve. Tenía mano de seminarista (mal augurio), pero juraba que quería ser ingeniero petrolero. Sus cabellos negros $y$ tupidos le recortaban el contorno de una cara llena de empuje y de ambición. Quería caerle bien a mi abuela; se le notaba. Aníbal Andrés bailó conmigo toda la noche, gentil. se le ve. No es de asos que tiran piedra y esconden la mano -me comentó Mamá Raquel al final de la noche [...] Pero aquella noche no supe cómo cuidarme de las mano de Aníbal Andrés. Fui yo quien lo besó primero; yo, quien lo incitó, lo admito. Pero no me esperaba la fuerza con que me agarró por debajo del traje, me desgarró la ropa interior, me metió los dedos cuclillas. Tamposa ponerme de manera como me mantuvo sujeta contra el suelo, mientras me metía su miembro duro entre las piernas." (SANTOS-FEBRES, 2009, p. 85)
"Vovó Raquel tinha disposto de tudo, até do par que me acompanharia a meu baile de quinze anos. Entre seus conhecidos, escolheu a Aníbal Andrés, afilhado de uma sobrinha. O rapaz era branco como a neve. Tinha mãos de seminarista (mal augúrio), mas jurava que queria ser engenheiro petroleiro. Seus cabelos negros e denso lhe recortava m o contorno de um rosto cheio de estímulo e de a mbição. Queria agradar bem minha avó; dava para notar. Aníbal Andrés dançou comigo toda a noite, gentil. -Esse rapaz vai chegar longe, se vê. Não é desses que atiram a pedra e escondem a mão - comentou-me Vovó Raquel no final da noite. [...] Mas, naquela noite não soube como me cuidar das mãos de Aníbal Andrés. Fui eu quem o beijou primeiro; eu, quem o incitou, admito. Mas, não esperava a força com que me aga rrou por debaixo do traje, me arrancou as roupas íntimas, meteu os dedos por dentro até me colocar de cócoras. Também não esperava a maneira como me manteve subjugada no chão, enqua nto metia seu membro duro entre as pernas (SANTOS-FEBRES, 2009, p. 85). ${ }^{5}$

Essa inserção da investigadora e protagonista, que em muito se assemelha aos seus 'objetos de estudo', volta a embaralhar o real e o ficcional, dessa vez da ficção em direção ao real, e propõe um outro efeito de leitura: a atualização da questão. Ao mesmo tempo que provoca a linhagem ficcional, ta mbém reafirma a permanência da violência sobre os corpos das mulheres negras como uma continuidade de uma época escravocrata. A inserção de um real, ainda que falseado, nesse caso, atualiza a problemática escravocrata em uma sociedade contemporânea ainda muito devedora das desigualdades racia is das quais é herdeira direta. Essa inserção traz a memória, a organiza, a expõe, a personaliza e a reconhece como um dado do presente.

Não é demais recorrer aos dados do Mapa da Violência ${ }^{6}$ que reafirma, uma vez mais, que as mulheres negras são as maiores vítimas de violência em nosso país, assim como nos demais países da América Latina e que, ainda que a violência contra as mulheres brancas demonstre queda, as perpetradas contra os corpos negros indicam crescimento. Esse corpo considerado 'disponível' para o homem branco continua a povoar o imaginário social, construído sobre uma base conhecidamente misógina e racista. Provocar as porosidades entre o real e o ficcional, reestabelece na literatura um elo com o espaço extra-ficcional, criando potencialidades de posiciona mento entre autora e leitor, a través, nesse caso, de reconhecimentos dos laços que unem o passado e o presente nas costuras entre a memória, a história e a ficção, mostrando as linhas e os tecidos entre os tempos. Como indica a autora na epígrafe: "esta obra é montada com documentos falsos e falsificados, reescritos com pedaços
6. O Mapa da violência: homicídios de mulheres no Brasil (2015), Waiselfisz, indica que, em acobo com as tendências em acordo violência contra a mulher branca apresenta constante diminuição enquanto a violência contra a mulher negra segue em crescimento no país: "O número de homicídios de brancas cai de 1.747 vitimas, em 2003, para 1.576, em 2013. Isso representa uma queda de $9,8 \%$ no total de homicídios do período. Já os homicídios mesmo período, passando de 1.864 para 2.875 vítimas." (p.30) e "As taxas de homicídio da populaça branca tendem, historicamente, a branca tendem, historicamente, a
cair, enquanto aumentam as taxas de mortalidade entre os negros. Por esse motivo, nos últimos anos, o Indice de vitimização da população egra cresceu de forma drástica" (p.29)
EM TESE
BELO HORIZONTE
v. 26
N. 1
JAN.-ABR. 2020
MARINGOLO; MARRA. Literatura Afro-brasileira: textualidade e corporeidade. P. 32-41 
7. "Esta obra está montada sobre documentos falsos, falsificados, reescritos con retazos de declaraciones de esclavos que recogide múltiples fuentes primarias y secundarias; que recombiné, (SANTOS-FEBRES, 2009, p. 109).

8. "recompongo (e ilustro) fragmentos del pasado. Los ofrezco al presente en tiempo hiperreal, un tiempo que pretende burlar la muerte de lo orgánico, la quietud (SANTOS, lenthes, de09, p. 109). de decla rações de escravos que eu coletei de várias fontes primárias e secundárias; que eu combinei, traduzi ou francamente inventei" (SANTOS-FEBRES, 2009, p.109) ${ }^{7}$.

E que "Recomponho e ilustro fragmentos do passado. Ofereço-os ao presente em tempo hiperreal, um tempo que pretende burlar a morte do orgânico, a quietude do papel, a lentidão dos fatos”. (SANTOS-FEBRES, 2009 p. 109) (op.cit, p.109) ${ }^{8}$

Salienta mos que o uso da codificação do real na obra ficcional, longe de ser um questionamento da ficção, a reafirma ao propor que se crie, a partir da ficção, até mesmo os efeitos que suposta mente somente o real seria capaz de gerar. Esse estabelecimento dos registros é, ao nosso ver, uma reafirmação do potencial do ficcional como criador de efeitos, inclusive daquele que se aproxima do real.

Abordar a violência, enquadrá-la, a tualizá-la e ficcionalizá-la, como proposto em Fe en disfraz, provoca a que se encontre a urgência do momento, forçando o leitor a se implicar. Podemos entender então, nesse caso a colocação do real como forma de exigência de ação imediata: no reestabelecimento da relação direta entre leitor e realidade social como uma abertura à ação de forma a criar um presente habitável e mais solidário.

\section{REFERENCIAS}

BARRET0, Juliana; GOMES, Flávio (orgs). Mulheres negras no Brasil escravista e do pós-emancipação. São Paulo; Selo negro, 2012, p. 67-83

CUTI. Literatura negro-brasileira. São Paulo: Selo Negro Edições, 2010.

EVARISTO, Conceição. Da representação à auto-representação da Mulher Negra na Literatura Brasileira. Revista Palmares: cultura afro-brasileira, ano 1, n. 1, p. 52-57, ago. 2005.

NARLOCH, Leandro. Achados e perdidos da história: escravos. Rio de Janeiro: estação Brasil, 2017, p.125-132.

PAIVA, Eduardo França. Alforrias. In: GOMES, Flávio santos, SCHWARCZ, Lilia Mortiz (orgs). Dicionário da escravidão e Liberdade: 50 textos críticos. 1a Edição, São Paulo; companhia das letras, 2018, p. 92-98.

PESAVENTO, Sandra Jatahy. História \& Literatura: uma velha-nova história. Nuevo Mundo, Mundos Nuevos, Debates, 2006. Disponível em:www.nuevomundo.revues.org/1560> . Acesso em 11 jul. 2018

RANCIÈRE, Jacques. A Partilha do Sensível: Estética e política. São Paulo: EXO Experimental org.; Ed. 34, 2005. Tradução de Mônica Costa Netto. 
RIBEIRO, Djamila. 0 que é lugar de fala? Belo Horizonte(MG) Letramento: Justificando, 2017, 35-51

SAFATLE, Vladimir. 0 circuito dos afetos. São Paulo: Autêntica, 2016. SANTOS-FEBRES, Mayra. Fe en disfraz. Florida, Alfaguara, 2009.

WAISELFISZ, Julio Jacobo. Mapa da Violência 2015: Homicídio de mulheres no Brasil. Disponível em www.mapadaviolencia.org. br Brasília - DF - 2015. Acesso em 26/11/2019.

XAVIER, Giovana. Entre personagens, tipologias e rótulos da $\mathrm{Cdi}$ ferença: a mulher escrava na ficção do Rio de janeiro no século XIX. In: XAVIER, Giovana; FARIAS, Juliana Barreto; GOMES, Flávio (Orgs.). Mulheres negras no Brasil escravista e do pós-emancipação. São Paulo: Selo negro, 2012, p. 67-83.

Recebido em: 31-11-2019

Aceito em: 21-07-2020 